\title{
Ensino religioso no Amapá: intolerância contra as religiões de matrizes africanas
}

\author{
Religious education in Amapá: intolerance \\ against religions of African origin
}

\section{Elivaldo Serrão Custódio*}

Faculdade EST, São Leopoldo, RS, Brasil

\section{Resumo}

O presente artigo tem como objetivo discutir sobre o Ensino Religioso (ER) e a intolerância contra as Religiões de Matrizes Africanas (RMA) no Espaço Escolar no Amapá. Acredito que, ao tratar das RMA no espaço escolar, precisamos implementar novos olhares sobre a nossa prática pedagógica, propiciando a construção da identidade do aluno e um espaço escolar capaz de lidar com as diferenças nas quais se inserem a escola e sua comunidade. Trata-se do resultado de um estudo exploratório de natureza qualitativa que adotou a pesquisa bibliográfica, a análise documental e a entrevista como forma de investigação. Como resultado desta pesquisa, verifica-se, por exemplo, que, no Amapá a Secretaria de Estado de Educação (SEED), mesmo com promulgação

\footnotetext{
ESC: Doutorando em Teologia, e-mail: elivaldo.pa@hotmail.com
} 
da Resolução do Conselho Estadual de Educação - CEE/AP n 14/2006, que dispõe sobre a oferta do ER no nível fundamental do sistema educacional do Estado, tem ignorado a participação das entidades civis constituídas pelas diferentes denominações religiosas no currículo da disciplina de ER. Constatou-se ainda que, no Amapá, entidades formadas por algumas igrejas cristãs, em trabalhos articulados com a SEED, respondem pelo ER, deixando de lado assim importantes representações locais como as entidades de matrizes africanas.

Palavras-chave: Ensino Religioso. Religiões de Matrizes Africanas. Intolerância Religiosa. Espaço escolar. Amapá.

\section{Abstract}

This article aims to discuss the Religious Education (RE) and intolerance against the African Dies Religions (RMA) in the school area in Amapá. I believe that by addressing the RMA at school, we need to implement new insights about our teaching practice, providing the construction of the identity of the student and school space capable of dealing with differences in which fall within the school and community. This is the result of an exploratory qualitative study which adopted the literature review, document analysis and interviews as a way to research. As a result of this research, we find, for example, that in Amapá, the State Department of Education (SEED), even with enactment of the Resolution of the State Board of Education - EEC / AP No. 14/2006, which provides for the supply of ER at the fundamental level of the educational system of the state, it has ignored the participation of civil organizations established by the different religious denominations in the curriculum of $R E$ discipline. I note further that in the Amapá, entities formed by some Christian churches in articulated work with SEED, account for ER, leaving aside important local representatives as the bodies of African origin.

Keywords: Religious Education. Arrays of African religions. Religious intolerance. School. Amapá. 


\section{Introdução ${ }^{1}$}

Ao nos aprofundarmos no conhecimento da história das Religiões de Matrizes Africanas (RMA) suscitou-nos a compreensão e ênfase de sua inclusão no ensino-aprendizagem como forma de combater o preconceito, a prática do racismo e a intolerância religiosa no âmbito da disciplina de Ensino Religioso (ER). Além disso, por ser de caráter obrigatório, com previsão legal na Constituição Federal (CF) de 1988, é necessário respeitar a diversidade cultural religiosa brasileira, não podendo deixar de contemplar todos os segmentos religiosos historicamente rejeitados no processo de escolarização da disciplina.

Com o propósito de contribuir com esta temática, este texto tem como objetivo discutir alguns aspectos relativos ao ER e as RMA no espaço escolar no Amapá. Trata-se do resultado de um estudo exploratório de natureza qualitativa que adotou a pesquisa bibliográfica, a análise documental e a entrevista como forma de investigação. $O$ texto é baseado na Dissertação de Mestrado apresentada no ano de 2014 ao Programa de Pós-Graduação em Direito Ambiental e Políticas Públicas da Universidade Federal do Amapá (UNIFAP).

O trabalho tem como objetivo atentar para questões como identidade, intolerância religiosa e racismo contra as RMA na disciplina de ER que se constitui hoje como área de conhecimento da base comum, de oferta obrigatória e de matrícula facultativa nos currículos do ensino fundamental das escolas públicas brasileiras. Sua ênfase está na formação cidadã do ser humano, enfatizando a dimensão antropológica, com ênfase no fenômeno religioso.

1 Uma versão preliminar deste artigo foi apresentada com o título "Ensino religioso e religiões de matrizes africanas no espaço escolar no Amapá: um diálogo necessário" no GT-1: Religião e Educação do V Congresso da Associação Nacional de Pós Graduação e Pesquisa em Teologia e Ciências da Religião (ANPTECRE), que ocorreu em Curitiba-PR, na PUCPR, no período de 09 a 11 de setembro de 2015, com a temática: Religião, Direitos Humanos e Laicidade. A presente versão, resulta de revisão do autor, após avaliação de parecerista deste periódico em dezembro de 2016. 


\section{Situando os caminhos da pesquisa}

Este estudo foi realizado no Estado do Amapá, em caráter exploratório. A pesquisa foi desenvolvida com base nos pressupostos e fundamentos na dialética, que implica na análise das contradições construídas historicamente nas relações materiais e ideológicas dos sujeitos sociais, isto é, uma reciprocidade da dinâmica sujeito/objeto como uma interação social que vai se concebendo na história (SEVERINO, 2007).

O método de abordagem da dialética, aqui entendida como a metodologia mais conveniente para discutirmos sobre a realidade social, possibilitando assim, uma discussão histórico-crítica sobre a disciplina de ER e as RMA no currículo escolar da educação pública estadual no Amapá. Optou-se por uma pesquisa crítico-dialética, utilizando-se a entrevista semiestruturada como principal instrumento na coleta de dados e sua análise por meio da Análise de Discurso (AD). Os sujeitos envolvidos nas entrevistas receberam uma codificação a fim de garantir o anonimato.

A entrevista semiestruturada foi realizada com onze (11) participantes, sendo estes, gestores e/ou técnicos de órgãos governamentais e não governamentais vinculados ou não à Secretaria Estadual de Educação do Amapá (SEED), responsáveis pela discussão, elaboração e execução de políticas educacionais que visem garantir a obrigatoriedade de inclusão da diversidade religiosa no currículo escolar da disciplina de ER. Na metodologia para a escolha dos sujeitos da pesquisa, considerou-se um corpus que não designasse apenas discursos da esfera oficial, mas, também, discursos de espaços menos controlados, esferas discursivas mais periféricas, menos filtradas pelos "mecanismos de controle discursivo" (FOUCAULT, 2008).

Para a análise e interpretação dos dados coletados valemo-nos do aporte teórico advindo do sociointeracionismo dialógico de Bakhtin (1997). O discurso tomado como objeto de estudo expressa posições políticas e ideológicas de um grupo social. Os sentidos que eles articulavam não estavam só nas palavras, nos textos, mas sim na relação com a exterioridade - nas condições em que foram produzidos, nos discursos em que eles se sustentaram e para onde apontaram, no lugar de onde falou o sujeito. 


\section{A influência africana no processo de formação da cultura brasileira: algumas considerações}

As RMA fazem parte da formação cultural brasileira. Mesmo aqueles que não sejam adeptos, acabam relacionando-se de alguma forma com as práticas culturais, sociais e simbólicas dessas religiosidades, como por exemplo, quando executamos um samba, ao comermos uma feijoada, ao recebermos os cuidados de uma benzedeira, ao tomarmos um chá de erva medicinal, ao usarmos plantas e objetos como amuletos ou para afastar mal olhado, etc.

Essas e outras práticas, relacionadas diretamente ou não com as religiões, fazem parte das nossas tradições e foram influenciadas pelas práticas e costumes de diversos povos africanos. E como o modo de vida das populações africanas esteve sempre ligados ao sagrado, a maioria dessas práticas possuem simbologias relativas ao religioso.

No contexto religioso afro-brasileiro, a complexidade das RMA ainda são de difícil compreensão para a sociedade, pois ao analisarmos os dados referentes ao Censo demográfico de 2000 e 2010, em que se propaga pelas informações contidas na página oficial do Instituto Brasileiro de Geografia e Estatística (IBGE), percebemos evidências de tão-somente o Candomblé e a Umbanda como religiões representativas do universo religioso afro-brasileiro (BRASIL, 2000, 2010).

Acredito que as religiões de origem africana no Brasil não podem ser medidas simplesmente pelo tamanho de seus contingentes ${ }^{2}$, mas, sobretudo, pela sua participação marcante na formação da cultura nacional não religiosa: na literatura, no teatro, cinema, televisão, nas artes plásticas, na música popular; sem falar do carnaval e suas escolas de samba, da culinária originária da comida típica e, sobretudo, da sua especial maneira de ver o mundo. Sendo assim, as RMA têm ganhado visibilidade, prestígio social e respeito.

Afirmar a existência de apenas dois modelos de RMA no Brasil é desprezar e até mesmo ignorar as produções acadêmicas sobre o tema,

2 Segundo dados do Censo do IBGE de 2010, cerca de 588.797 (0,3\%) habitantes se autodeclararam adeptos a religião de Umbanda e Candomblé no Brasil (BRASIL, 2010). 
que reconhecem a pluralidade religiosa, como exemplo: Tambor-de-mina do Maranhão; Xangô de Recife; Batuque no Rio Grande do Sul; todas de grande expressão nacional; além de outras, como Catimbó, Jurema, Pajelança e a macumba, depois umbanda, no Rio de Janeiro e em São Paulo (COSTA NETO, 2010).

É pertinente ressaltar que a trajetória das RMA no Brasil começa pela proibição e imposição da religiosidade católica com a conversão ao cristianismo, surgindo à estratégia da perpetuação do culto das RMA por meio do sincretismo religioso. Desde o início da colonização, os africanos de alguma forma buscavam cultuar seus deuses ocultamente através da religião católica.

O negro por muito tempo teve que deixar de lado seus deuses africanos e cultuar unicamente a religião do branco. No entanto, o catolicismo que por muito tempo se apresentou como cultura hegemônica, não fez oposições, que não pudessem ser vencidas. Abrindo assim, espaço para que o negro pudesse manter uma dupla ligação religiosa. É certo que embora as religiões afro-brasileiras tenham sido perseguidas e dependentes do catolicismo em suas origens, hoje, mesmo em passos lentos, as religiões de origem negra começaram a se desligar do catolicismo ${ }^{3}$.

Compreender a dimensão da inserção das RMA no ER, bem como suas relações dentro do espaço escolar, seja por questões identitárias de descendentes de escravizados africanas e africanos constitui o rompimento com um paradigma em voga desde a colonização ibérica, marcada por valores de uma religião tradicionalmente católica "na qual se nasce sem necessidade de adesão ou escolha” (CURY, 1988, p. 13). Segundo Cunha Jr. (2009) não se pode conhecer a cultura brasileira na sua amplitude sem reconhecer a existência das religiões trazidas pelos africanos para o Brasil.

Verifica-se, então, na pesquisa que o ER, segundo as prerrogativas nacionais, deverá ser ofertado em todos os níveis da educação fundamental, observados os requisitos para a qualificação dos docentes, sempre consultando às religiões existentes atualmente no Brasil, e, não se pode a

3 Esse fato é bem evidente observando os resultados do último Censo de 2010 que declarou que os católicos passaram de 73,6\% em 2000 para 64,6\% em 2010 (BRASIL, 2010). Embora o perfil religioso da população brasileira mantenha, em 2010, a histórica maioria católica, esta religião vem perdendo adeptos desde 0 primeiro Censo, realizado em 1872. 
qualquer pretexto, excluir as RMA na formação do currículo, sob pena de incidir em crime de responsabilidade de todos aqueles servidores públicos responsáveis pela educação básica nos Estados, no Distrito Federal e nos Municípios brasileiros.

Erisvaldo Pereira dos Santos ao se referir às RMA no contexto brasileiro nos afirma que

Embora a liberdade de consciência e de crença seja um dos direitos e garantias fundamentais do cidadão conforme a Constituição Brasileira, bem como o livre exercício dos cultos religiosos, os organismos de implementação de políticas educacionais continuam desconsiderando a existência de religiões de matrizes africanas no Brasil (SANTOS, 2010, p. 48).

Devemos lembrar que a discussão quanto ao reconhecimento das RMA como patrimônio cultural da humanidade não é uma temática recente. O não reconhecimento da religião dos negros, a intolerância religiosa com relação às religiões de herança africanas, e a crítica/negação das mesmas em oposição à matriz judaico-cristã, vêm dificultando a construção de uma cultura de respeito à diversidade.

Observamos que na literatura contemporânea sobre as RMA que estas se encontram instaladas no espaço brasileiro e que se apresentam como religiões estruturalmente organizadas, com crenças e ritos, portanto, possuidoras de fenômenos religiosos. Assim, essa discussão no campo da educação, entre outros, é pertinente.

Conforme Santos (2005) embora no Brasil se percebam um vasto repertório de códigos socioculturais e educativos da população afrodescendente, ainda assim, são poucos os/as pesquisadores/as do campo da educação que realizam investigações sobre a referida temática. Apesar da liberdade de consciência e de crença seja um dos direitos e garantias fundamentais do cidadão existente na CF de 1988 (Art. 5º - inciso VI), bem como o livre exercício dos cultos religiosos, os organismos de implementação de políticas educacionais (PE) continuam desconsiderando a existência de RMA no território nacional.

As RMA sempre foram vistas pela sociedade branca dominante de forma estereotipada. Inicialmente como feitiçaria e manifestação 
demoníaca, depois como prática criminosa e finalmente como índice de patologia psíquica, de doença mental.

Williams (2012) ao tratar da escravidão em seus estudos, declara que a escravidão não nasceu do racismo; ao contrário, o racismo moderno é consequência da escravidão. Embora esta visão ainda hoje seja vista assim por muitos, acredito que foi o racismo que deu sustentação à escravidão.

Desde o início da colonização, os africanos foram considerados pela Igreja Católica como seres sem alma, próximos aos animais que, portanto poderiam ser escravizados e tratados como coisas, como "peças". Era necessário justificar de alguma forma a prática criminosa da escravização, e o único argumento seria negar aos africanos a própria condição humana, classificando-os como selvagens que desconheciam a organização política, as leis, a moral e a religião. A fé cristã era considerada, evidentemente, a única verdadeira (MUSEU AFRO-BRASILEIRO, 2006).

Pelo exposto, é possível perceber que a presença do negro na formação social do Brasil foi decisiva para dotar a cultura brasileira dum patrimônio mágico-religioso, pois entendemos que os cultos trazidos pelos africanos deram origem a uma variedade de manifestações que aqui encontraram conformação específica através de uma multiplicidade sincrética que resultou do encontro das matrizes negras com o catolicismo do branco, bem como do encontro das religiões indígenas e posteriormente com o espiritismo kardecista (PRANDI, 1995).

\section{Identidade, intolerância religiosa e racismo no espaço escolar}

A presença do negro na formação social é de suma importância para a conceituação, afirmação, valorização e construção da identidade religiosa e identidade étnica racial brasileira. Até porque, segundo Fonseca e Silva Bento (2009, p. 6), "o continente africano além ser o berço da humanidade é, também, o das civilizações". Obviamente faz-se necessário, conforme Munanga (2002), resgatar a identidade do negro no Brasil. Entretanto, este autor esclarece que, 
A busca da identidade, no nosso caso o Brasil, apesar da importância, não é uma coisa fácil; é problemática. Essa identidade passa pela cor da pele, pela cultura, ou pela produção cultural do negro; passa pela contribuição histórica do negro na sociedade brasileira; na construção da economia do país com seu sangue; passa pela recuperação de sua história africana, de sua visão do mundo, de sua religião [...] trata-se de um processo de consciência (MUNANGA, 1996, p. 225).

Percebemos em nossas pesquisas que a "identidade negra" é um tema que ganha destaque no processo de discussão, tanto no seio do Movimento Negro, como em meio a alguns cientistas sociais, que tentam além de desmascarar a democracia racial, resgatar nossa cultura negra. A identidade negra, assim, como em outros processos identitários, se constrói gradativamente, num movimento que envolve inúmeras variáveis, causas e efeitos. $\mathrm{E}$ é entendida como uma construção social, histórica, cultural e plural.

Na visão de Moreira (2008), a identidade resulta das relações do homem com o meio, sendo construída nas relações sociais, ao longo da vida em meio às interações e identificações com diferentes pessoas e grupos com os quais convive ou estabelece contatos. Esse aspecto formativo identitário também é criado por atos de linguagem, particularmente, por enunciados que fazem com que alguma coisa aconteça. Assim, o que foi dito contribui para reforçar uma identidade que, em muitos casos, pensaríamos estar apenas descrevendo.

Ninguém nega o fato de que todos nós gostaríamos que o Brasil fosse uma verdadeira democracia racial, ou seja, que fôssemos uma sociedade em que os diferentes grupos étnico-raciais vivessem em situação real de igualdade social, racial e de direitos. No entanto, lembra-nos Gomes (2006, p. 56) de que "os dados estatísticos sobre as desigualdades raciais na educação, no mercado de trabalho e na saúde e sobre as condições de vida da população negra, revelam que tal situação não existe de fato".

Observa-se que o preconceito está inserido na sociedade brasileira por meio do cotidiano dos indivíduos, sendo altamente prejudicial para a população negra, tanto nas relações sociais (família, escola, bairro, trabalho e etc.) quanto nos meios de comunicação. O preconceito é um fator importante para a expansão da discriminação étnica, visto que um indivíduo 
preconceituoso racialmente, não aceita de maneira positiva o contato com negros na vida social.

Infelizmente o Brasil vive uma situação singular, pois a discriminação pautada na cor e o racismo são uma realidade inegável (CAVALLEIRO, 2001; FOSTER, 2004). Sobre o racismo na escola, Fernandes (2008, p. 246) expressa que "a escola brasileira não está preparada para corrigir as deficiências funcionais da família e, muito menos para lidar com os desajustamentos reais ou potenciais das minorias raciais, étnicas e raciais".

Nesse sentido, a eliminação do racismo é uma responsabilidade também da escola e deve estar incluída em seus objetivos. Mas, é um desafio a ser enfrentado e que esbarra em uma série de dificuldades, em nível educacional como, por exemplo, a bagagem racista que os docentes carregam como fruto de sua própria formação, a omissão em relação ao problema, entre outros.

O racismo é um problema que também está atrelado a toda uma longa história e pode estar sendo realimentado sutilmente, através das memórias e das narrativas que penetram na escola. Diante dessa perspectiva, observa-se que o racismo apresenta-se como uma ideologia que permite o domínio sobre um grupo, por exemplo, judeu, negro ou muçulmano, pautado apenas em atributos negativos imputados a cada um deles. Assim, o racismo atribui a inferioridade a uma raça e está baseado em relações de poder, legitimadas pela cultura dominante (MUNANGA, 1996).

As RMA sempre foram vistas como cercadas de mistérios, seus ritos não são conhecidos pela grande maioria da população, o que por certo contribui para o processo de intolerância religiosa, uma vez que seus mitos são preservados e retransmitidos de geração em geração. Sendo assim, para compreendermos as práticas de discriminação de gênero, raça, e classe na escola, temos que desvendar a raiz de atitudes opressoras, rever os processos de ensinar e de aprender para transformar a sociedade.

Entendemos que intolerância religiosa significa a não aceitação, o desrespeito e a exclusão daqueles que têm religiões diferentes da nossa. A intolerância pode expressar-se pelo simples ato de afirmar que nossa religião seja a única verdadeira ou superior, desprezando todas as demais religiões.

Ao dedicar todo o oitavo capítulo de seu livro Educação nos terreiros e como a escola se relaciona com crianças de candomblé, sobre a questão do ER nas escolas públicas, Caputo (2012) observa em sua pesquisa, uma certa 
imposição do desvalor dos cultos afro-brasileiros, particularmente do candomblé, ao mesmo tempo uma pretensão de legitimidade do cristianismo. Relata a autora que, ao contrário do que poderíamos pensar, a aliança católico-evangélica contra os afro-brasileiros não se limita somente ao tempo e ao espaço do ER. Muito mais do que isso, ela permeia todo o currículo escolar e mal esconde seu racismo.

Caputo (2012) observa que há muito preconceito nas escolas contra crianças e jovens adeptos as RMA. Expressa que todos os tipos de preconceitos identificados foram relatados por crianças e jovens de terreiros entrevistados durante sua pesquisa. Além de identificar discriminações nas entrevistas realizadas com professores e professoras da rede pública.

Os educandos que ocupam muitas vezes lugares de destaque nos terreiros ao qual pertencem e amam, nem sempre conseguem assumir a sua religiosidade na escola. A autora faz um paralelo entre um grupo de meninos que conseguem assumi-la e outro que se diz católico, frequenta missa e se integra aos rituais da igreja com o objetivo de serem aceitos socialmente, fugindo da dor da discriminação e da exclusão. E isso se constitui na intolerância religiosa que em vez de ser minimizada dentro da escola, encontra nesta, um lugar por excelência de muita contradição e preconceito (CAPUTO, 2012, p. 199-206).

Concordo com Foster (2001, p. 68-69), quando afirma que analisar a questão do racismo e a discriminação racial na escola não é tarefa das mais simples. Em virtude da complexidade do problema e das várias tentativas realizadas pela escola para escamotear o problema racial, toda a aproximação ao universo escolar que traga preocupações dessa natureza constitui uma experiência melindrosa e bastante delicada.

A construção de uma imagem negativa do negro tem marcos históricos importantes, que se iniciam no contato dos europeus com o continente africano. Diante dessa situação, é importante recuperarmos raízes para reconstruir a identidade negra, mas precisamos também, simultaneamente, preocupar-nos com as questões referidas às condições sociais e culturais de hoje que afetam diretamente as condições de vida do negro.

Ainda que muitas mudanças tenham ocorrido nas últimas décadas, mesmo hoje é possível nos depararmos com uma série de preconceitos que põem em risco a seriedade das religiões afro-brasileiras. $\mathrm{Na}$ escola, muitas 
vezes a matriz africana é ignorada, embora esteja claramente presente, inclusive, na identidade de nossos alunos, o que torna imprescindível um diálogo mais constante entre essa cultura e a vida escolar.

A discriminação das RMA é bastante observada por Mariano (2007), em seu trabalho intitulado Demonização dos cultos afro-brasileiros. O autor ao desenvolver um argumento sobre a longa história de perseguição aos cultos afro-brasileiros nos remete ao papel desempenhado pela Igreja Católica em demonizar toda e qualquer prática religiosa advinda do Continente Africano.

Lembro que essa atitude preconceituosa e mesmo a demonização dos cultos afro, por parte da Igreja Católica é de herança colonial, atrelada à visão eurocêntrica de cultura. Entretanto, tanto a teologia da cultura quanto a teologia das religiões que se firmaram em torno do Concilio Vaticano II, mudaram esta postura para outra: mais respeitosa e inclusiva, com documentos de revisão dos preconceitos e formação de evangelizadores com esta nova abordagem, como por exemplo, o Documento Nostra Aetate, do Vaticano $\mathrm{II}^{4}$, o Documento Diálogo e Anúncio, do Pontifício Conselho para o Diálogo Inter-religioso ${ }^{5}$, e também, o Documento de Aparecida, 2007, p. 235-2396.

As RMA pressupõem um grande desafio para trabalharmos no espaço escolar devido à intolerância religiosa que existe neste espaço laico e cristão ao mesmo tempo. Parece-nos que a ideia de incluir a religiosidade africana

4 Nostra Aetate, promulgada em 28 de outubro de 1965, é a declaração sobre o relacionamento da Igreja Católica com as igrejas não cristãs elaboradas e aprovadas pelo Concílio Vaticano II, isto é, um documento que fala sobre as relações da igreja com as religiões não cristãs, expressando de forma positiva a perspectiva de abertura, compromisso ético, superação de preconceitos e acolhimento por parte da igreja católica com as diversas religiões.

50 documento, aprovado em abril de 1990, foi promulgado em 19 de maio de 1991 pelo Pontifício Conselho para o Diálogo Inter-religioso - Congregação para a Evangelização dos Povos, durante o pontificado de João Paulo II. Segundo Maçaneiro (s.d., p.01) o documento desenvolve uma avaliação teológica das religiões e propõe um autêntico diálogo inter-religioso.

6 Documento de Aparecida - Texto Conclusivo da V Conferência Geral do Episcopado Latino-Americano e do Caribe. Aparecida, 13 a 31 de maio de 2007. Destaque para a parte específica que trata da "integração dos indígenas e afro-americanos", bem como do tópico “Caminhos de reconciliação e solidariedade" onde os textos expressam sobre o espaço e o destaque para a identidade própria dos povos indígenas e afro-americanos, sua cultura, história, tradições e ainda, a necessidade de a lgreja respeitar a alteridade, defendendo ao mesmo tempo suas terras ameaçadas e lutando por superar, as discriminações, os preconceitos e o racismo tão presentes na sociedade.

Rev. Pistis Prax., Teol. Pastor., Curitiba, v. 9, n. 1, 259-280, jan./abr. 2017 
como um componente curricular que resgate a memória da população negra, ou de incluir medidas de ação afirmativa nas políticas educacionais que venham a solucionar as distorções e as desigualdades secularmente produzidas, não é bem vista por muitos.

A escola é o lugar de construção, não só do conhecimento, mas também da identidade, de valores, de afetos. Percebemos que embora na história do Brasil, a sociedade brasileira foi formada a partir de heranças culturais europeias, indígenas e africanas, a maioria de nossos sistemas educacionais não contemplam, de maneira equilibrada, essas três contribuições. Há indícios de que a pedagogia e os livros didáticos apresentam uma visão eurocêntrica, perpetuando estereótipos e preconceitos.

Acredito que a escola é o lugar privilegiado para apreender as diferenças e possibilidades de transformação. Sabemos que a escola não é um espaço para proselitismo religioso, mas é um espaço, no qual os estudantes precisam conhecer a diversidade que existe no Brasil e no mundo e aprender a respeitar as diferenças e a verdade de cada um. Não se pode ignorar a identidade religiosa do educando no espaço escolar.

\section{A presença negra no Amapá: alguns subsídios para a compreensão do racismo e da intolerância religiosa}

A presença negra no Amapá nesse momento merece especial atenção, pois é necessário conhecermos um pouco de sua trajetória histórica para podermos compreender como se desenrolou o processo discriminatório ao longo dos anos. Para Foster (2004, p. 185), rever a história do negro no Amapá,

[...] Implica num movimento um pouco mais amplo: o da compreensão de alguns aspectos da questão racial na sociedade amapaense, englobando os processos de resgate e ressignificação das memórias dos negros dessa região e da própria história do negro na região amazônica.

Segundo Morais (2009), os negros africanos chegaram ao Amapá em 1749. Nesta ocasião, os negros vieram fugidos de Belém e fundaram no Rio 
Anauerapucu um quilombo. Não demorou muito para os escravos serem descobertos por caçadores de índios e por isso o quilombo foi abandonado. Ressalta Morais (2009) que os negros chegaram ao Amapá oficialmente no ano de 1751 através de Mendonça Furtado, então governador do Maranhão e Grão-Pará. O governador pretendia colonizar da melhor maneira possível às terras amapaenses e, por isso, importou famílias de colonos portugueses que habitavam a Ilha dos Açores e foi através dessas famílias que muitos escravos foram trazidos para o Amapá. Em seguida, Macapá recebeu famílias vindas do Rio de Janeiro, Pernambuco, Bahia e Maranhão que também trouxeram muitos escravos.

Outro acontecimento foi necessário para a inserção de mais escravos no Amapá: a transferência de 163 famílias portuguesas que foram instaladas na Nova Mazagão e com essas famílias vieram 103 escravos. O referido município de Mazagão fica distante da Capital Macapá, por apenas 2 horas e 30 minutos por via fluvial ou 7 minutos por via aérea.

Segundo Nunes Filho (2009, p. 227), com o advento das Vilas de Macapá, assim como de Mazagão e Vistosa de Madre de Deus, houve uma migração significativa no século XVIII e os primeiros escravos africanos chegaram ao Amapá com o surgimento do Tratado de Utrecht ${ }^{7}$. Esses africanos vieram de várias regiões do Brasil e das Guianas fugidos da escravidão, sendo que foi por meio dos ameríndios locais que eles instalaram-se na região Norte e no Amapá formando vários quilombos.

Com a construção da Fortaleza de São José em Macapá, a presença do negro era constante. Segundo Foster (2004) a Fortaleza de São José guarda lugares sinistros que confirmam violências e até assassinatos dos negros. Acredito que, com base em depoimentos orais e alguns escritos ${ }^{8}$, possam ter existido casos em que os senhores, por falta de herdeiros, tenham deixados seus bens e/ou terras para antigos escravos, como por exemplo, o Quilombo do Curiaú localizado a $8 \mathrm{~km}$ do centro do município de Macapá-AP.

70 Tratado de Utrecht, assinado em 1713 pela França e por Portugal, estabelecia o Oiapoque como fronteira entre os dois reinos na América do Sul, pelo que o Brasil, como "herdeiro do Império Português", alegava o direito de exercer soberania sobre as terras ao sul daquele curso fluvial.

8 Sobre esse assunto, conferir Sebastião Menezes da Silva, Curiaú: sua vida, sua História, s/d. Sebastião Menezes da Silva Curiaú: resistência de um povo. Secretaria Municipal do Meio Ambiente, 2004. 
Em Macapá, com a abolição dos escravos, os governantes se sentiram incomodados pela cotidiana presença dos negros na capital amapaense e, por isso, decidiram transferi-los, segregá-los e excluí-los para a periferia de Macapá. Atualmente esta periferia é o bairro do Laguinho, onde até hoje moram descendentes dos escravos, os afrodescendentes, que continuaram mantendo uma tradição baseada na cultura africana.

No bairro do Laguinho está localizada a União dos Negros do Amapá (UNA) onde acontecem encontros, oficinas, seminários, palestras, apresentações culturais e artísticas que engrandecem e valorizam a cultura afro-brasileira e a história do povo amapaense. É uma iniciativa que demonstra a capacidade da população negra em resistir à opressão. Segundo Pereira (2008, p. 68-69) no Centro de Cultura Negra funcionam e interferem em seu gerenciamento várias organizações civis como a Federação dos Cultos Afro-Brasileiros, o Movimento Mocambo, entre outros.

É certo de que o governo de Janary Nunes no Amapá ${ }^{9}$ contribuiu de forma significativa para o enfraquecimento da cultura negra no Estado. Em nossa visão, houve nesse período, em especial na Capital do Estado, o primeiro saneamento étnico do centro da cidade, quando os negros tiveram que deixar suas casas para que fosse viabilizada a construção de conjuntos residenciais para assessores do governo territorial e outros funcionários.

Segundo Maciel (2001), era de se esperar uma reação negativa das pessoas contra o remanejamento. Todavia, aconteceu de forma pacífica, pois não houve, por parte dos moradores e das lideranças, resistências aparentemente. Isso só foi possível devido a cooptação das lideranças negras partidárias da política de Janary.

Nossa autora afirma ainda que essa situação foi tão lamentável que apesar de algumas resistências iniciais, o poder de convencimento dos líderes foi tamanho, que os negros não só se conformaram em deixar suas casas e partir para o lugar a eles destinado, como também desenvolver uma espécie de adoração à figura de Janary.

Além dessas situações, percebemos também que houve um grande movimento repressivo das manifestações culturais africanas a partir

9 Capitão Janary Gentil Nunes nomeado em 29/12/1943 no Rio de Janeiro pelo Presidente da República Getúlio Vargas. Chegou a Macapá no dia 25/01/1944. 
da chegada dos padres italianos do Pontifício Instituto das Missões Estrangeiras (PIME). Esses religiosos por razões preconceituosas encaravam o Marabaixo ${ }^{10}$ como macumba, folclore, ocasião para bebidas, orgias e outras manifestações da influência do diabo, jamais como legítima manifestação religiosa da alma popular. Maciel (2001, p. 36) destaca que o longo período de domínio político de Janary Nunes no Amapá, de 1943 a 1970, foi determinante "para introjetar essa 'divisão étnica' como natural".

Foster (2004, p. 207-208) nos relata que a invisibilidade dos negros no Amapá, não se resume somente aos aspectos físicos. Ela também se manifesta em termos simbólicos. A autora acredita que principalmente no âmbito educacional, essa invisibilidade ganha corpo e forma nas ausências e critérios do negro nos currículos escolares, nos discursos distantes da prática que, via de regra, deixam entrever posições dúbias e até contraditórias, nas atitudes sutis de discriminação racial, ainda que se deva reconhecer os esforços que pretendem dar mais visibilidade aos negros, ainda que essas iniciativas estejam restritas aos aspectos mais específicos das manifestações culturais.

Sobre a intolerância religiosa contra as RMA no Amapá, Videira (2013), nos relata que o ER trata-se de um campo de saber complexo porque os professores em sua maioria fazem apologia a suas religiões individuais e os conteúdos que ministram são proselitistas ${ }^{11}$ e por isso, marginalizam e demonizam as RMA.

Concordo com Videira (2013, p. 34) quando declara que embora o esfacelamento da cultura negra no Estado do Amapá esteja atrelado a diversos fatores - apesar das resistências do movimento negro local - a inclusão da cultura afro amapaense no currículo da educação básica deve

10 É hoje uma manifestação cultural popular afro amapaense, nascendo assim das diferentes etnias que foram transportadas de suas terras de origem para o Brasil. É uma mistura de dança, religiosidade e ancestralidade africana que tem orgulho, determinação e resistência. É ainda, um ritual que compõe várias festas católicas populares em oito comunidades negras da área metropolitana de Macapá e Santana no Estado do Amapá. Em relação ao significado do nome Marabaixo, "os depoimentos deixam claro que pouco se sabe a respeito de sua origem, muito embora possa lembrar a penosa travessia dos africanos nas naus escravistas mar - a baixo, daí havendo a aglutinação entre as silabas e originando-se a palavra Marabaixo" (VIDEIRA, 2009, p. 99).

${ }^{11}$ Por proselitismo entendemos as expressões de dogmatismo que resultam em discriminação social, cultural ou religiosa. 0 proselitismo parte da certeza de uma verdade única no campo religioso e ignora a diversidade.

Rev. Pistis Prax., Teol. Pastor., Curitiba, v. 9, n. 1, 259-280, jan./abr. 2017 
ter atenção especial, não somente no conteúdo programático, mas, sobretudo, dentro do projeto político pedagógico das escolas.

\section{Considerações finais}

De um modo em geral, o que entendemos com toda essa problematização é que o Brasil precisa avançar em muito na discussão sobre a liberdade religiosa e o tratamento igualitário entre todas as matrizes religiosas existentes no Brasil. E neste cenário, a intolerância religiosa é considerada, atualmente, umas das questões mais difíceis de serem enfrentadas pelos educadores, pelas escolas e inclusive pelo espaço universitário, cuja ausência de tolerância viola a dignidade da pessoa humana, resguardada pela Declaração dos Direitos Humanos.

Dentro das concepções de políticas públicas de Estado e de Governo, com base em alguns documentos que tive acesso, bem como nas entrevistas realizadas, se observa a necessidade de uma releitura das políticas educacionais excludentes das RMA no processo de construção da disciplina e na formação de docentes capacitados (as) para reconhecer as identidades dentro das diferenças culturais, pois percebemos que boa parte das dificuldades encontradas a respeito do tratamento dado as RMA no ER, se encontram, em parte, na incapacidade de se entender a religião como um objeto de estudo.

Ao longo desta pesquisa, foi ressaltado que foram enfrentadas muitas dificuldades no acesso à pesquisa documental, pois poucos foram os lugares onde os sujeitos da pesquisa tinham em sua posse a documentação solicitada e/ou disponibilizaram-nos para análise. Parece-nos não haver uma preocupação por parte de alguns órgãos com a catalogação e arquivamento dos documentos pertinentes ao objeto de estudo, muito menos o interesse em organizar um espaço que disponibilize esses documentos para o público em geral, especialmente para pesquisadores/as e docentes.

Apesar desses problemas de acesso, os documentos que nos foram disponibilizados para a análise auxiliaram na contextualização do fenômeno pesquisado e ajudaram a elucidar suas relações e conexões mais profundas e densas com a realidade examinada. A sistematização 
e análise dos documentos selecionados ocorreram simultaneamente à análise das entrevistas.

Quanto à análise e resultados desta pesquisa, foi verificado, por exemplo, com base principalmente nas entrevistas, que a Secretaria de Estado de Educação (SEED) mesmo com promulgação da Resolução do Conselho Estadual de Educação (CEE/AP) no 14/2006, que dispõe sobre a oferta do ER no nível fundamental do sistema educacional do Estado, tem ignorado a participação das entidades civis constituídas pelas diferentes denominações religiosas no currículo da disciplina de ER, tal como prescrito no $\S 2^{\circ}$ do Art. 33 da Lei no 9.394/1996, alterado pela Lei no 9.475/1997.

Constatou-se ainda, com base nas entrevistas, que no Amapá, entidades formadas por algumas igrejas cristãs que, em trabalhos articulados com a SEED respondem pelo ER, deixam de lado importantes representações locais, como as entidades de matrizes africanas. A inclusão das RMA no ER, do ponto de vista prático, é inexistente e não contemplada nos currículos da disciplina, na formação dos docentes, nas orientações pedagógicas, cujos ensinamentos estão delineados sob o viés cristão, sem qualquer alusão às práticas antirracistas.

Outro aspecto que nos chama a atenção, diz respeito ao discurso de alguns entrevistados no que concerne à educacional escolar para a população negra, em especial sobre a discussão e reflexão das RMA na disciplina de ER na educação pública estadual no Amapá, pois estes revelam traços sutis de racismo e discriminação.

Portanto, acredito que ao tratarmos da disciplina de ER e as RMA no espaço escolar, é preciso implementar novos olhares sobre a nossa prática pedagógica, propiciando a construção da identidade do/a discente e um espaço escolar capaz de lidar com as diferenças na qual se insere a escola e sua comunidade.

\section{Referências}

BAKHTIN, M. Os gêneros do discurso. In: BAKHTIN, M. Estética da criação verbal. Trad. Maria Ermantina Galvão Gomes Pereira. 2 $2^{\mathrm{a}}$ ed. São Paulo: Martins Fontes, 1997. p. 277-326. 
BRASIL. Conselho Estadual de Educação do Amapá. Resolução n 14/2006 de 15 de março de 2006. Dispõe sobre a oferta do ensino religioso no nível fundamental, do sistema educacional do Estado do Amapá. Disponível em: <http://www.gper.com. br/bibliotecadownload.php?arquivoId=136>. Acesso em: 28 ago. 2011.

BRASIL. Instituto Brasileiro de Geografia e Estatística (IBGE). Censo Demográfico 2010. Disponível em: <ftp://ftp.ibge.gov.br/Censos/Censo_Demografico_2010/ Caracteristicas_Gerais_Religiao_Deficiencia/tab1_4.pdf>. Acesso em: 30 jun. 2012.

BRASIL. Instituto Brasileiro de Geografia e Estatística (IBGE). Censo Demográfico 2000. Disponível em: <http://www.ibge.gov.br/home/estatistica/populacao/ censo2000/populacao/religiaoCenso2000.pdf〉. Acesso em: 30 jun. 2012.

CAPUTO, S. G. Educação nos terreiros e como a escola se relaciona com crianças de candomblé. Rio de Janeiro: Pallas, 2012.

CAVALLEIRO, E. Educação antirracista: compromisso indispensável para um mundo melhor. In: CAVALLEIRO, E. (Org.). Racismo e antirracismo na educação: repensando nossa escola. São Paulo: Selo Negro, 2001.

CONCÍLIO VATICANO II. Nostra Aetate: sobre a relação da Igreja com as religiões não cristãs. São Paulo: Paulinas, 1976.

COSTA NETO, A. G. Ensino religioso e as religiões matrizes africanas no Distrito Federal. 2010. 198f. Dissertação (Mestrado em Educação) - Universidade de Brasília, Brasília, 2010. Disponível em: <http://repositorio.bce.unb.br/bitstre am/10482/7083/1/2010AntonioGomesdaCostaNeto.pdf〉. Acesso em: 29 out. 2011.

CUNHA JR, H. Candomblés: como abordar esta cultura na escola. Revista Espaço Acadêmico, n. 102, p. 97-103, nov. 2009. Disponível em: <http://periodicos.uem. br/ojs/index.php/EspacoAcademico/article/viewFile/7738/4810〉. Acesso em: 16 nov. 2012.

CURY, C. R. J. Ideologia e Educação Brasileira: Católicos e liberais. 4ª ed. São Paulo: Cortez Editora - Autores Associados, 1988. 
DECLARAÇÃO NOSTRA AETATE SOBRE A IGREJA E AS RELIGIÕES NÃOCRISTÃS. Disponível em: <http://www.vatican.va/archive/hist_councils/ii_vatican_council/documents/vat-ii_decl_19651028_nostra-aetate_po.html>. Acesso em: 15 jan. 2017.

CONFERÊNCIA GERAL DO EPISCOPADO LATINO-AMERICANO E DO CARIBE APARECIDA, 13-31 DE MAIO DE 2007 - DOCUMENTO FINAL DA V CONFERÊNCIA. Disponível em: <http://www.dhnet.org.br/direitos/cjp/a_pdf/ cnbb_2007_documento_de_aparecida.pdf $>$. Acesso em: 15 jan. 2017.

FERNANDES, F. A integração do negro na sociedade de classes: o legado da raça branca, v. 1. São Paulo: Globo, 2008.

FOSTER, E. L. S. 500 anos de racismo na sociedade e na escola: do silêncio à palavra. In: V Congresso de Ciências Humanas, letras e artes - Humanidades, Universidade e Democracia, 28 a 31 de agosto de 2001, Ouro-Preto, MG. Caderno de resumos, 2001. Anais, p. 68. Disponível em: <http://www.ichs.ufop.br/conifes/anais/CMS/ccms02.htm>. Acesso em: 29 out. 2011.

FOSTER, E. L. S. Racismo e Movimentos Instituintes na Escola. Niterói: 2004. $398 f$. Tese (Doutorado em Educação) - Faculdade de Educação, Universidade Federal de Fluminense, Rio de Janeiro, 2004. Disponível em: <http://www.bdtd.ndc. uff.br/tdearquivos/2/TDE-2005-03-15T14:39:57Z70/Publico/Parte\%201-TeseEugenia\%20Foster.pdf >. Acesso em: 29 out. 2011.

FONSECA, D. J.; SILVA BENTO, M. A. África. Desconstruindo Mitos. In: A África e o Brasil Afro-Brasileiro História, Cultura, Ciência e Arte. São Paulo, 2009.

FOUCAULT, M. A ordem do discurso: Aula inaugural no Collège de France, pronunciada em 02 de dezembro de 1970. 16 a ed. Trad. Laura Fraga de Almeida Sampaio. São Paulo: Loyola, 2008.

GOMES, N. L. Alguns termos e conceitos presentes no debate sobre relações raciais no Brasil: uma breve discussão. In: BRASIL. Ministério da Educação. Educação antirracista: caminhos abertos pela Lei Federal n. 10.639/03. Brasília: Ministério da Educação, Secretaria de Educação Continuada, Alfabetização e Diversidade, 2006. 
MAÇANEIRO, M. Documento "Diálogo e Anúncio", apreciação teológica das religiões e caminhos para o diálogo inter-religioso. 2009. Disponível em: <http://www.cnbb. org.br/site/images/arquivos/files_48a333312f509.pdf >. Acesso em: 15 de jan. 2017.

MARIANO, R. Pentecostais em ação: a demonização dos cultos afro-brasileiros. In: SILVA, Vagner Gonçalves (Org.) Intolerância religiosa: impactos de neopentecostalismo no campo religioso afro-brasileiro. São Paulo: Edusp, 2007.

MACIEL, A. S. Conversa de amarra preto: a trajetória histórica da União dos Negros do Amapá: 1986-2000. 2001. Dissertação (Mestrado em História) Universidade Estadual de Campinas/Instituto de Filosofia e Ciências Humanas, São Paulo, 2001.

MORAIS, P. D. História do Amapá: O passado é o espelho do presente. Macapá: JM Editora Gráfica, 2009.

MOREIRA, A. F. B. Reflexões sobre currículo e identidade: implicações para a prática pedagógica. In: MOREIRA, A. F. B.; CANDAU, V. M. Multiculturalismo: diferenças culturais e práticas pedagógicas. Petrópolis: Vozes, 2008.

MUNANGA, K. As facetas de um racismo silencioso. In: SHWARCZ, L. M.; QUEIROZ, R. S. (Org.). Raça e diversidade. São Paulo: EDUSP, 1996.

MUNANGA, K. A identidade negra no contexto da globalização. Ethos Brasil, Ano I, n. 1. São Paulo: UNESP, 2002.

MUSEU AFRO-BRASILEIRO (MAFRO). Centro de Estudos Afro-orientais da Universidade Federal da Bahia. Setor religiosidade afro-brasileira. Projeto de Atuação Pedagógica e Capacitação de Jovens Monitores. Material do professor, 2006. Disponível em: <http://www.mafro.ceao.ufba.br/userfiles/files/Material\%20do\%20 Professor\%20-\%20Afro-Brasileiro.pdf $>$. Acesso em: 18 jul. 2012.

NUNES FILHO, E. P. Formação histórica, econômica, social, política e cultural do Amapá: descrição e análise do processo de formação histórica do Amapá. In: OliVEIRA, A.; RODRIGUES, R. (Org.). Amazônia, Amapá: Escritos da História. Belém: Paka-Tatu, 2009. 
PEREIRA, D. L. Candomblé no Amapá: história, memória, imigração e hibridismo cultural. Belém: 2008. 229f. Dissertação (Mestrado em História) - Universidade Federal do Pará, Instituto de Filosofia e Ciências Humanas, Programa de PósGraduação em História Social da Amazônia, Belém, 2008.

PRANDI, R. Raça e Religião. Novos Estudos CEBRAP, n. 42, p. 113-129, jul. 1995. SANTOS, E. P. dos. A educação e as religiões de matriz africana: motivos da intolerância. Anais da $28^{a}$ Reunião da ANPED. GT Afro-Brasileiros e Educação. Caxambu: ANPED, 2005. p. 01-17. Disponível em: <www.anped.org.br/reunioes/28/textos/gt21/gt21241int.doc>. Acesso em: 10 nov. 2012.

SANTOS, E. P. dos. Formação de professores e religiões de matrizes africanas: um diálogo necessário. Belo Horizonte: Nandyala, 2010. (Coleção Repensando África, volume 4).

SEVERINO, A. J. Metodologia do trabalho científico. 23 ed. São Paulo: Cortez, 2007. VIDEIRA, P. L. Batuques, folias e ladainhas: a cultura do quilombo do Cria-ú em Macapá e sua educação. Fortaleza: Edições UFC, 2013.

VIDEIRA, P. L. Marabaixo, dança afrodescendente: significando a identidade étnica do negro amapaense. Fortaleza: Edições UFC, 2009.

WILLIAMS, E. Capitalismo e escravidão. Trad. Denise Bottmann. Prefácio Rafael de Bivar Marquese. $1^{a}$ ed. São Paulo: Companhia das Letras, 2012.

Recebido: 20/05/2016

Received: 05/20/2016

Aprovado: 21/01/2017

Approved: 01/21/2017 